\title{
Biofilm formation as a novel phenotypic feature of adherent-invasive Escherichia coli (AIEC)
} Margarita Martinez-Medina ${ }^{1}$, Plínio Naves ${ }^{2}$, Jorge Blanco ${ }^{3}$, Xavier Aldeguer ${ }^{4}$, Jesus E Blanco ${ }^{3}$, Miguel Blanco ${ }^{3}$, Carmen Ponte ${ }^{2}$, Francisco Soriano², Arlette Darfeuille-Michaud ${ }^{5}$ and L Jesus Garcia-Gil*1

\begin{abstract}
Address: ${ }^{1}$ Laboratory of Molecular Microbiology, Biology Department, University of Girona, Spain, ${ }^{2}$ Department of Medical Microbiology and Antimicrobial Chemotherapy, Fundación Jiménez Díaz-Capio, Madrid, Spain, ${ }^{3}$ E. coli Reference Laboratory, Faculty of Veterinary, University of Santiago de Compostela, Lugo, Spain, ${ }^{4}$ Gastroenterology Department, Dr. Josep Trueta Hospital, Girona, Spain and ${ }^{5}$ Laboratory of Intestinal Bacterial Pathogenesis, USC-INRA 2018, JE 2526 University of Auvergne, Clermont-Ferrand, France

Email: Margarita Martinez-Medina - marga.martinez@udg.edu; Plínio Naves - plinionaves@gmail.com; Jorge Blanco - jorge.blanco@usc.es; Xavier Aldeguer - doctoraldeguer@yahoo.es; Jesus E Blanco - jeba@lugo.usc.es; Miguel Blanco - mba@lugo.usc.es;

Carmen Ponte-MCponte@fjd.es; Francisco Soriano - FSoriano@fjd.es; Arlette Darfeuille-Michaud - arlette.darfeuille-michaud@u-clermont1.fr; L Jesus Garcia-Gil* - jesus.garcia@udg.edu

* Corresponding author
\end{abstract}

Published: 21 September 2009

BMC Microbiology 2009, 9:202 doi:10.1186/147I-2180-9-202
Received: II May 2009

Accepted: 21 September 2009

This article is available from: http://www.biomedcentral.com/I47I-2I80/9/202

(C) 2009 Martinez-Medina et al; licensee BioMed Central Ltd.

This is an Open Access article distributed under the terms of the Creative Commons Attribution License (http://creativecommons.org/licenses/by/2.0), which permits unrestricted use, distribution, and reproduction in any medium, provided the original work is properly cited.

\begin{abstract}
Background: Crohn's disease (CD) is a high morbidity chronic inflammatory disorder of unknown aetiology. Adherent-invasive Escherichia coli (AIEC) has been recently implicated in the origin and perpetuation of $C D$. Because bacterial biofilms in the gut mucosa are suspected to play a role in $C D$ and biofilm formation is a feature of certain pathogenic $E$. coli strains, we compared the biofilm formation capacity of 27 AIEC and 38 non-AIEC strains isolated from the intestinal mucosa. Biofilm formation capacity was then contrasted with the AIEC phenotype, the serotype, the phylotype, and the presence of virulence genes.
\end{abstract}

Results: Specific biofilm formation (SBF) indices were higher amongst AIEC than non-AIEC strains $(P=0.012)$. In addition, $65.4 \%$ of moderate to strong biofilms producers were AIEC, whereas $74.4 \%$ of weak biofilm producers were non-AIEC $(P=0.002)$. These data indicate that AIEC strains were more efficient biofilm producers than non-AIEC strains. Moreover, adhesion $(P=0.009)$ and invasion $(P=0.003)$ indices correlated positively with higher SBF indices. Additionally, motility $(100 \%, \mathrm{P}<0.00 \mathrm{I}), \mathrm{HI}$ type flagellin $(53.8 \%, \mathrm{P}<0.00 \mathrm{I})$, serogroups $\mathrm{O} 83(19.2 \%, \mathrm{P}=0.008)$ and $\mathrm{O} 22$ $(26.9 \%, P=0.00 \mathrm{I})$, the presence of virulence genes such as sfa/focDE $(38.5 \%, P=0.003)$ and ibeA $(26.9 \%, P=0.017)$, and $B 2$ phylotype $(80.8 \%, P<0.00 I)$ were frequent characteristics amongst biofilm producers.

Conclusion: The principal contribution of the present work is the finding that biofilm formation capacity is a novel, complementary pathogenic feature of the recently described AIEC pathovar. Characterization of AIEC specific genetic determinants, and the regulatory pathways, involved in biofilm formation will likely bring new insights into AIEC pathogenesis. 


\section{Background}

Crohn's disease (CD) is a chronic-relapsing inflammatory bowel disease (IBD) that can affect the entire gastrointestinal tract. The incidence rate varies from 1 to 20 cases per $10^{5}$ people per year and is still rising in some countries [1]. Although the aetiology of CD remains elusive to date, it is widely accepted that several factors are involved in the onset or perpetuation of the disease. These factors include genetic and immunologic features that confer host susceptibility, and external or environmental factors such as microorganisms and lifestyle [2,3]. Environmental factors play an important role because there is a low concordance between identical twins, both for CD and ulcerative colitis (UC) [4]. The involvement of microbes in the onset or perpetuation of inflammation has been extensively studied [5-10]. To date, some pathogens have been proposed as causative agents. In particular, adherent-invasive E. coli (AIEC) is increasing in relevance because it has been reported to be more prevalent in $\mathrm{CD}$ patients than in controls in several countries (France [11], United Kingdom $[12]$, USA $[13,14]$, and Spain [15]). AIEC strains have the ability to adhere to and to invade intestinal epithelial cells in vitro as well as to survive and replicate within macrophages without inducing host-cell death and promoting tumour necrosis factor (TNF) $\alpha$ release. No unique genetic sequences have been described for AIEC, nor have specific genes of diarrhoeagenic pathovars been detected yet for AIEC, but they do carry many virulence-associated genes characteristic of extraintestinal pathogenic E. coli (ExPEC) $[13,15,16]$. For that reason, AIEC pathovar has been speculated to be closely related to ExPEC pathovar.

In a previous work, we observed that some CD patients showed a high diversity of AIEC subtypes associated to their intestinal mucosa [15]. In a given patient, we could detect up to 8 different clones as assessed by pulsed field gel electrophoresis. On the other hand, AIEC abundance, richness and diversity were lower in non-IBD controls. We hypothesized that the higher diversification of clones could be explained by a long-term colonization of AIEC in CD. Biofilm formation can be a way to persistently colonize the intestinal mucosa [17], as has been reported for commensal microbiota in healthy subjects [18]. Moreover, for certain organisms such as the species belonging to the uropathogenic E. coli pathovar (UPEC) - which form intracellular biofilms [19] - and to the enteroaggregative pathogenic E. coli pathovar (EAEC) - which form thick biofilms that adhere to the apical side of enterocytes [20], active biofilm formation is feature of their pathogenesis. For that reason, the primarily aim of this work was to determine the biofilm formation capacity of AIEC strains and non-AIEC strains, both isolated from the intestinal mucosa.

We herein report a new phenotypic feature of the recently described AIEC pathovar which is the ability to form bio- films in vitro. In addition, we illustrate those seropathotypes and phylotypes more frequently found amongst biofilm producers.

\section{Results \\ AIEC strains are stronger biofilm producers than non-AIEC strains isolated from the intestinal mucosa}

The present study involved a collection of $65 \mathrm{E}$. coli strains, 27 of which (41.5\%) were classified as AIEC by their ability to adhere to and invade intestinal epithelial cells, and to survive and replicate within macrophages, as previously described [11] (Table 1).

Within the category of weak biofilm producers, $74.4 \%$ of strains were non-AIEC, whereas $65.4 \%$ of moderate to strong biofilm producers were AIEC $(P=0.002)$. Amongst these AIEC strains, 22.2\% were strong biofilm producers, and $40.7 \%$ were moderate biofilm producers (Table 2). Similar results were obtained when SBF index values were compared. As shown in Figure 1, the mean SBF index was higher in AIEC strains than in non-AIEC $\left(\mathrm{SBF}_{\mathrm{AIEC}}=0.65 \pm\right.$ $\left.0.53 ; \mathrm{SBF}_{\mathrm{NON}-\mathrm{AIEC}}=0.36 \pm 0.36 ; \mathrm{P}=0.012\right)$.

Interestingly, higher adhesion indices from both AIEC and non-AIEC strains correlated with higher SBF indices $(P=0.009)$. Moreover, the correlation was even stronger between the invasion and biofilm formation capacities of AIEC strains $(P=0.003)$. No correlation was observed with the ability of AIEC strains to survive and replicate within macrophages (Figure 2).

\section{Nonmotile strains were unable to form biofilms and, amongst motile strains, those with $\mathrm{HI}$ flagellar type showed the highest biofilm formation indices}

An additional factor that was associated with biofilm formation was the motility of the strains. Regardless of adhesion and invasion abilities, motile strains showed higher SBF indices than nonmotile strains $\left(\mathrm{SBF}_{\mathrm{MOTILE}}=0.61 \pm\right.$ $\left.0.48, \mathrm{SBF}_{\text {NONMOTILE }}=0.14 \pm 0.13 ; \mathrm{P}<0.001\right)$. All strains producing moderate-strong biofilms were motile, whereas strains classified as weak biofilm producers were heterogeneous in their motility capacities. In concordance, the isogenic mutant LF82- $\Delta$ fliC which is nonmotile, non-flagellated and express only few type 1 pili, did not display the ability to form biofilms $(\mathrm{SBF}=0,393 \pm 0,084)$ in contrast to LF82 wild type $(\mathrm{SBF}=1.641 \pm 0.326)$.

Moreover, SBF indices were specifically higher for the $\mathrm{H} 1$ serotype as shown in Figure 3. All H1 serotypes were moderate-strong biofilm producers. In contrast, only 12 out of $33(36.4 \%)$ of strains with other $\mathrm{H}$ types were classified within this category (Table 3 ).

To determine whether motility and AIEC-like phenotype were intrinsically related factors, the frequency of motile and nonmotile strains within AIEC and non-AIEC strains 
Table I: Phenotypic and genotypic characteristics of the bacterial strains used in this study.

\begin{tabular}{|c|c|c|c|c|}
\hline Id Strain & Origin & Serotype & Phylo. & Virulence gene carriage \\
\hline AIECI9 & C & ONT: H- & A & $i u c D, f i m H, f i m A v_{M T 78}$ \\
\hline AIEC07 & C & O22: H7 & $\mathrm{BI}$ & papC, iucD, fimH \\
\hline AIEC04 & C & O6: HNT & B2 & papC, sfalfocDE, iucD, hlyA, cnfl, fimH, fimAv ${ }_{M T 8}$ \\
\hline AIECIO & C & OI59: H34 & A & $\mathrm{fimH}$ \\
\hline AIEC06 & C & O6: H5 & B2 & papC, sfalfocDE, hlyA, cnfI, fimH, cdtB \\
\hline AIEC08 & C & $\mathrm{O} 25: \mathrm{H} 4$ & B2 & $p a p C, i u c D, i b e A, f i m H, c d t B$ \\
\hline AIEC25 & $C D$ & O6: H3I & B2 & papC, hlyA, cnfl, fimH \\
\hline AIEC2I & $C D$ & O6: HI & B2 & $p a p C$, iucD, hlyA, cnfl, fimH \\
\hline AIECI2 & $C D$ & O26: H- & B2 & $p a p C$, afa/draBC, iucD, fimH \\
\hline AIEC20 & $C D$ & OII: HI8 & $\mathrm{D}$ & $p a p C$, afa/draBC, iucD, fimH \\
\hline AIECI7 & $C D$ & ONT: HNT & D & neuC, ibeA, fimH \\
\hline AlEC05 & $C D$ & Ol: H- & B2 & papC, neuC, fimH \\
\hline AIEC02 & $C D$ & O8: $\mathrm{H} 2 \mathrm{I}$ & B2 & papC, neuC, fimH \\
\hline AIECOI & $C D$ & O6: $\mathrm{HI}$ & B2 & sfa/focDE, iucD, fimH \\
\hline AIEC09 & $C D$ & ONT: H- & B2 & papC, sfalfocDE, iucD, hlyA, cnfl, fimH, fimAv ${ }_{M T 8}$ \\
\hline AIEC24 & $C D$ & ONT: H- & A & $i u c D, f i m H, f i m A v_{M T 78}$ \\
\hline AIEC23 & $C D$ & O5: HNT & A & $\mathrm{fimH}$ \\
\hline AlECII & $C D$ & O22: $\mathrm{HI}$ & B2 & afaldraBC, iucD, fimH \\
\hline AIECI5-I & $C D$ & O22: HI & B2 & $\mathrm{fimH}$ \\
\hline AIECI4-I & $C D$ & O22: $\mathrm{HI}$ & B2 & $\mathrm{fimH}$ \\
\hline AIECI6-2 & $C D$ & O22: $\mathrm{HI}$ & B2 & $\mathrm{fimH}$ \\
\hline
\end{tabular}




\begin{tabular}{|c|c|c|c|c|}
\hline LF82 & $C D$ & O83: $\mathrm{HI}$ & B2 & $i b e A, f i m H, f i m A v_{M T 78}$ \\
\hline AIECI3 & UC & O25: H4 & B2 & papC, iucD, hlyA, cnfl, ibeA, fimH, cdtB \\
\hline PPI6 & Sepsis & O83: $\mathrm{HI}$ & B2 & ibeA, fimH, fimAv ${ }_{M T 78}$ \\
\hline FV7563 & UTI & O25: H4 & B2 & $a f a / d r a B C, i u c D, f i m H$ \\
\hline OL96A & UTI & O6: HI & B2 & papC, sfalfocDE, iucD, hlyA, cnfl, fimH \\
\hline PP2I5 & Sepsis & O6: $\mathrm{HI}$ & B2 & papC, sfalfocDE, iucD, hlyA, cnfl, fimH \\
\hline ECG-046 & C & ONT: H29 & BI & iucD, pCDV432 \\
\hline ECG-060 & C & O102: H6 & $\mathrm{D}$ & papC, iucD, fimH \\
\hline ECG-037 & C & Ol: H- & $\mathrm{D}$ & papC, neuC, iucD, fimH, fimAv ${ }_{M T 78}$ \\
\hline ECG-016 & C & O55: H- & A & neuC, iucD, fimH \\
\hline ECG-0I7 & C & O22: HI8 & B2 & sfalfocDE, fimH \\
\hline ECG-022 & C & OI5: $\mathrm{H}-$ & A & afa/draBC, neuC, iucD, fimH \\
\hline ECG-043 & C & O83: $\mathrm{HI}$ & B2 & $i b e A, f i m H, f i m A v_{M T 78}$ \\
\hline ECG-04I & C & O2: $\mathrm{H}-$ & B2 & papC, sfa/focDE, iucD, hlyA, cnfl, fimH, cdtB \\
\hline ECG-012 & C & OI8: $\mathrm{HI}$ & B2 & papC, sfalfocDE, iucD, hlyA, cnfl, fimH \\
\hline ECG-025 & C & O6: $\mathrm{H} 3 \mathrm{I}$ & B2 & papC, hlyA, cnfl, fimH \\
\hline ECG-049 & C & OI5: HI6 & B2 & papC, iucD, fimH \\
\hline ECG-03I & C & O161: H4 & $\mathrm{D}$ & iucD, fimH \\
\hline ECG-023 & C & ONT: H- & At & iucD, fimH, fimAv ${ }_{M T 78}$ \\
\hline ECG-054 & C & Ol4: H- & $\mathrm{D}$ & papC, iucD, fimH \\
\hline ECG-008 & C & Ol4: H7 & B2 & papC, iucD, ibeA, fimH, fimAv ${ }_{M T 78}$ \\
\hline ECG-004 & C & O22: H7 & BI & $\mathrm{fimH}$ \\
\hline ECG-013 & C & $\mathrm{Ol} 8: \mathrm{HI}$ & B2 & papC, sfa/focDE, iucD, hlyA, cnfl, fimH \\
\hline
\end{tabular}


Table I: Phenotypic and genotypic characteristics of the bacterial strains used in this study. (Continued)

\begin{tabular}{|c|c|c|c|c|}
\hline ECG-055 & C & Ol7: HI8 & D & papC, iucD, fimH \\
\hline ECG-024 & C & Ol74: H- & $\mathrm{BI}$ & $\mathrm{fimH}$ \\
\hline ECG-064 & $C D$ & O166: $\mathrm{H} 21$ & $\mathrm{BI}$ & $\mathrm{fimH}$ \\
\hline ECG-042 & $C D$ & O7: H6 & B2 & $f i m H, f i m A v_{M} 78$ \\
\hline ECG-00I & $C D$ & O6: $\mathrm{H} 3 \mathrm{I}$ & B2 & papC, hlyA, cnfl, fimH \\
\hline ECG-005 & $C D$ & O4: H5 & B2 & papC, sfalfocDE, hlyA, cnfl, fimH \\
\hline ECG-065 & $C D$ & Ol4I: H- & A & $f i m H, f i m A v_{M T 78}$ \\
\hline ECG-047 & $C D$ & OII9: H2I & $\mathrm{D}$ & iucD, fimH \\
\hline ECG-019 & $C D$ & ONT: H- & A & \\
\hline ECG-0I8 & $C D$ & ONT: $\mathrm{H}-$ & A & iucD \\
\hline ECG-002 & $C D$ & Ol75: H- & $\mathrm{BI}$ & $\mathrm{fimH}$ \\
\hline ECG-034 & $C D$ & O127: H28 & $\mathrm{D}$ & iucD, fimH \\
\hline ECG-02I & $C D$ & O54: H2I & $\mathrm{BI}$ & $\mathrm{fimH}$ \\
\hline ECG-063 & $C D$ & ONT: H2I & $\mathrm{BI}$ & $\mathrm{fimH}$ \\
\hline ECG-056 & $C D$ & ONT: HI8 & $\mathrm{D}$ & $p a p C$, afaldraBC, iucD, fimH \\
\hline ECG-057 & $C D$ & OII: HI8 & $\mathrm{D}$ & papC, afaldraBC, iucD, fimH \\
\hline ECG-053 & $C D$ & OII: H- & $\mathrm{D}$ & $p a p C$, afa/draBC, iucD, fimH \\
\hline ECG-059 & $C D$ & ONT: HI8 & $\mathrm{D}$ & papC, iucD, fimH \\
\hline ECG-026 & $C D$ & $\mathrm{OI}: \mathrm{H}-$ & B2 & papC, neuC, ibeA, fimH, fimAv ${ }_{M T 78}$ \\
\hline ECG-0I5 & $C D$ & O2: $\mathrm{H} 6$ & B2 & papC, sfalfocDE, neuC, hlyA, cnfl, fimH \\
\hline ECG-009 & $C D$ & O83: $\mathrm{HI}$ & B2 & sfalfocDE, neuC, iucD, ibeA, fimH, fimAv ${ }_{M T 78}, c d t B$ \\
\hline
\end{tabular}




\begin{tabular}{|c|c|c|c|c|c|c|c|c|c|c|}
\hline \multirow{2}{*}{$\begin{array}{l}\text { Id Strain } \\
\text { AIECI9 }\end{array}$} & \multirow{2}{*}{$\begin{array}{c}\text { AIEC } \\
+\end{array}$} & \multicolumn{2}{|c|}{ I_ADH (mean \pm SD) } & \multicolumn{2}{|c|}{ I_INV (mean \pm SD) } & \multicolumn{2}{|c|}{ I_REPL (mean \pm SD) } & \multicolumn{2}{|c|}{ SBF (mean \pm SD) } & \multirow{2}{*}{$\begin{array}{c}\text { BFC } \\
W\end{array}$} \\
\hline & & 2.40 & \pm 0.65 & 0.111 & \pm 0.016 & 1568.1 & \pm 1726 & 0.053 & \pm 0.019 & \\
\hline AIEC07 & + & 20.00 & \pm 13.50 & 0.565 & \pm 0.392 & 1692.6 & \pm 296.8 & 2.391 & \pm 0.317 & $\mathrm{~s}$ \\
\hline AlEC04 & + & 21.50 & \pm 9.00 & 0.320 & \pm 0.016 & 584.7 & \pm 418.5 & 0.772 & \pm 0.132 & $M$ \\
\hline AIECIO & + & 6.00 & \pm 0.98 & 0.226 & \pm 0.192 & 1413.7 & \pm 51.4 & 0.610 & \pm 0.175 & M \\
\hline AlEC06 & + & 10.25 & \pm 3.25 & 0.177 & \pm 0.019 & 1717.7 & \pm 307.9 & 1.212 & \pm 0.233 & $\mathrm{~s}$ \\
\hline AIEC08 & + & 1.13 & \pm 0.18 & 0.172 & \pm 0.066 & 104.8 & \pm 49.7 & 0.397 & \pm 0.133 & W \\
\hline AlEC25 & + & 2.75 & \pm 1.33 & 0.482 & \pm 0.129 & 775.9 & \pm 128.3 & 0.437 & \pm 0.129 & w \\
\hline AlEC2I & + & 17.00 & \pm 7.75 & 0.109 & \pm 0.013 & 1297.1 & \pm 625.2 & 0.558 & \pm 0.205 & $M$ \\
\hline $\mathrm{AIECI} 2$ & + & 22.25 & \pm 4.00 & 0.142 & \pm 0.017 & 193.7 & \pm 55.9 & 0.125 & \pm 0.052 & w \\
\hline AIEC20 & + & 14.25 & \pm 6.25 & 0.125 & \pm 0.098 & 343.9 & \pm 244.6 & 0.284 & \pm 0.116 & W \\
\hline AIECI7 & + & 21.75 & \pm 17.50 & 0.266 & \pm 0.055 & 1053.0 & \pm 75.0 & 0.840 & \pm 0.286 & $M$ \\
\hline AlEC05 & + & 9.50 & \pm 2.25 & 0.202 & \pm 0.042 & 704.9 & \pm 714.0 & 0.181 & \pm 0.072 & w \\
\hline AlEC02 & + & 0.85 & \pm 1.03 & 0.802 & \pm 0.035 & 2187.8 & \pm 4.8 & 0.106 & \pm 0.035 & w \\
\hline AIECOI & + & 16.00 & \pm 9.25 & 0.284 & \pm 0.106 & 1566.7 & \pm 1060 & 0.700 & \pm 0.177 & M \\
\hline AIEC09 & + & 5.25 & \pm 4.00 & 0.216 & \pm 0.010 & 2562.3 & \pm 240.6 & 0.068 & \pm 0.035 & w \\
\hline AlEC24 & + & 1.98 & \pm 1.40 & 0.309 & \pm 0.138 & 1625.6 & \pm 115.6 & 0.076 & \pm 0.044 & w \\
\hline AlEC23 & + & 9.75 & \pm 0.70 & 0.568 & \pm 0.148 & 2362.1 & \pm 250.2 & 0.300 & \pm 0.093 & W \\
\hline AlECII & + & 0.83 & \pm 0.19 & 2.125 & \pm 1.164 & 739.4 & \pm 477.4 & 0.537 & \pm 0.129 & $M$ \\
\hline AIECI5-I & + & 25.00 & \pm 15.75 & 2.261 & \pm 1.349 & 776.9 & \pm 304.8 & 1.090 & \pm 0.407 & $\mathrm{~s}$ \\
\hline AIECI4-I & + & 4.25 & \pm 3.50 & 0.508 & \pm 0.081 & 847.9 & \pm 512.8 & 0.654 & \pm 0.153 & $M$ \\
\hline AIECI6-2 & + & 10.00 & \pm 1.425 & 0.305 & \pm 0.159 & 659.7 & \pm 437.0 & 0.502 & \pm 0.134 & M \\
\hline LF82 & + & 25.00 & \pm 5.25 & 2.261 & \pm 0.011 & 776.9 & \pm 252.4 & 1.641 & \pm 0.326 & $\mathrm{~s}$ \\
\hline
\end{tabular}


Table 2: AIEC phenotype and category of biofilm formation ability of the strains. (Continued)

\begin{tabular}{|c|c|c|c|c|c|c|c|c|c|c|}
\hline $\mathrm{AlECI} 3$ & + & 1.20 & \pm 4.25 & 0.104 & \pm 0.000 & 1045.9 & \pm 181.6 & 0.772 & \pm 0.211 & M \\
\hline PPI6 & + & 8.00 & \pm 0.98 & 1.400 & \pm 0.081 & 225.9 & \pm 541.2 & 1.012 & \pm 0.268 & $\mathrm{~s}$ \\
\hline FV7563 & + & 6.75 & \pm 6.00 & 0.129 & \pm 0.072 & 470.0 & \pm 264.0 & 0.518 & \pm 0.226 & M \\
\hline OL96A & + & 5.25 & \pm 5.00 & 0.388 & \pm 0.159 & 457.5 & \pm 259.3 & 1.208 & \pm 0.202 & $S$ \\
\hline PP215 & + & 0.83 & \pm 0.60 & 0.453 & \pm 0.350 & | 425.4 & \pm 229.4 & 0.546 & \pm 0.139 & M \\
\hline ECG-046 & - & - & & $<0.1$ & & - & & 0.004 & \pm 0.010 & w \\
\hline ECG-060 & - & - & & $<0.1$ & & - & & 0.127 & \pm 0.041 & w \\
\hline ECG-037 & - & - & & $<0.1$ & & - & & 0.042 & \pm 0.024 & W \\
\hline ECG-016 & - & - & & $<0.1$ & & - & & 0.134 & \pm 0.085 & w \\
\hline ECG-017 & - & - & & $<0.1$ & & - & & 1.074 & \pm 0.286 & $S$ \\
\hline ECG-022 & - & - & & $<0.1$ & & - & & 0.143 & \pm 0.090 & W \\
\hline ECG-043 & - & - & & $<0.1$ & & - & & 1.187 & $\pm 0.51 \mathrm{I}$ & $\mathrm{s}$ \\
\hline ECG-04I & - & - & & $<0.1$ & & - & & 0.301 & \pm 0.123 & w \\
\hline ECG-012 & - & - & & $<0.1$ & & - & & 0.741 & \pm 0.259 & M \\
\hline ECG-025 & - & - & & $<0.1$ & & - & & 0.154 & \pm 0.043 & w \\
\hline ECG-049 & - & - & & $<0.1$ & & - & & 0.384 & \pm 0.160 & w \\
\hline ECG-03I & - & - & & $<0.1$ & & - & & 0.067 & \pm 0.024 & w \\
\hline ECG-023 & - & 0.90 & \pm 0.65 & 0.052 & \pm 0.003 & - & & 0.038 & \pm 0.020 & w \\
\hline ECG-054 & - & - & & $<0.1$ & & - & & 0.209 & \pm 0.128 & w \\
\hline ECG-008 & - & - & & $<0.1$ & & - & & 0.817 & \pm 0.288 & M \\
\hline ECG-004 & - & - & & $<0.1$ & & - & & 1.113 & \pm 0.234 & $\mathrm{~s}$ \\
\hline ECG-013 & - & - & & $<0.1$ & & - & & 0.516 & \pm 0.332 & M \\
\hline ECG-055 & - & - & & $<0.1$ & & - & & 0.108 & \pm 0.033 & W \\
\hline
\end{tabular}


Table 2: AIEC phenotype and category of biofilm formation ability of the strains. (Continued)

\begin{tabular}{|c|c|c|c|c|c|c|c|c|c|}
\hline ECG-024 & - & - & & $<0.1$ & & - & 0.037 & \pm 0.016 & W \\
\hline ECG-064 & - & - & & $<0.1$ & & - & 0.553 & \pm 0.171 & M \\
\hline ECG-042 & - & - & & $<0.1$ & & - & 0.348 & \pm 0.147 & W \\
\hline ECG-00I & - & - & & $<0.1$ & & - & 0.299 & \pm 0.106 & W \\
\hline ECG-005 & - & - & & $<0.1$ & & - & 0.404 & \pm 0.103 & W \\
\hline ECG-065 & - & - & & 0.061 & \pm 0.070 & - & 0.026 & \pm 0.022 & W \\
\hline ECG-047 & - & 1.93 & \pm 1.95 & 0.259 & \pm 0.084 & - & 0.007 & \pm 0.016 & W \\
\hline ECG-019 & - & - & & $<0.1$ & & - & 0.439 & \pm 0.057 & W \\
\hline ECG-018 & - & - & & $<0.1$ & & - & 0.058 & \pm 0.042 & W \\
\hline ECG-002 & - & - & & $<0.1$ & & - & 0.039 & \pm 0.023 & W \\
\hline ECG-034 & - & - & & $<0.1$ & & - & 0.293 & \pm 0.101 & W \\
\hline ECG-02I & - & 6.00 & \pm 4.00 & 0.033 & \pm 0.011 & - & 0.311 & \pm 0.117 & W \\
\hline ECG-063 & - & - & & $<0.1$ & & - & 0.195 & \pm 0.064 & W \\
\hline ECG-056 & - & - & & $<0.1$ & & - & 0.124 & \pm 0.047 & W \\
\hline ECG-057 & - & 11.75 & \pm 7.25 & 0.013 & \pm 0.011 & - & 0.241 & \pm 0.094 & W \\
\hline ECG-053 & - & - & & $<0.1$ & & - & 0.262 & \pm 0.083 & W \\
\hline ECG-059 & - & - & & $<0.1$ & & - & 0.200 & \pm 0.137 & W \\
\hline ECG-026 & - & - & & $<0.1$ & & - & 0.418 & \pm 0.189 & W \\
\hline ECG-015 & - & 5.25 & \pm 2.75 & 0.038 & \pm 0.004 & - & 1.035 & \pm 0.219 & $S$ \\
\hline ECG-009 & - & - & & $<0.1$ & & - & 1.346 & \pm 0.205 & S \\
\hline
\end{tabular}

Adhesion, invasion, intra-macrophage replication, and biofilm formation indices are specified. Abbreviators: AIEC: AIEC phenotype (+: strains that adhere to and invade Intestine-407 cells and that were able to survive and/or replicate within 1774 macrophages in vitro); I_ADH: adhesion index; I_INV: invasion index; I_REPL: replication index; SBF: specific biofilm formation index; BFC: Biofilm formation category; W: weak biofilm producer; M: moderate
biofilm producer; and S: strong biofilm producer. 


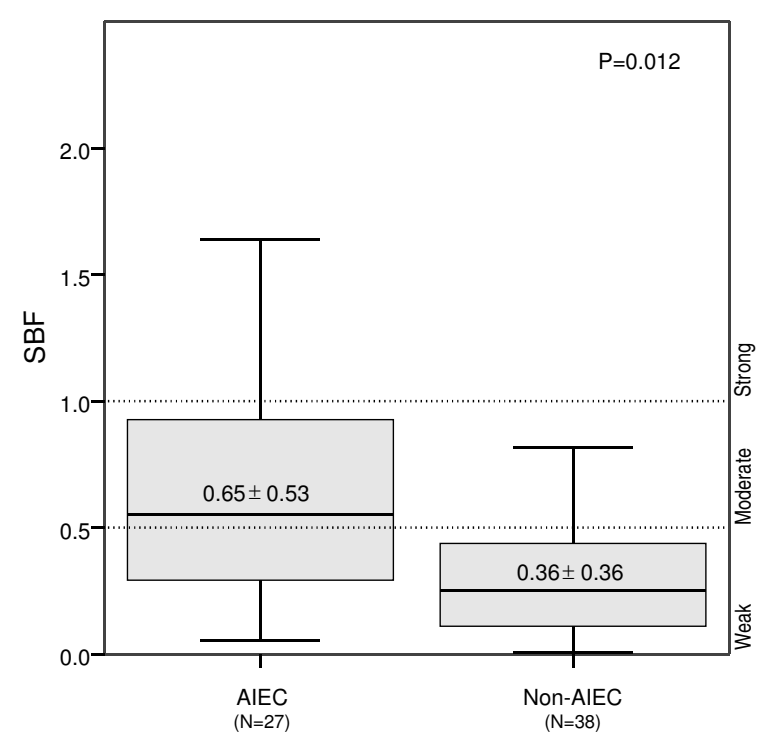

Figure I

Mean specific biofilm formation (SBF) index of AIEC and mucosa-associated non-AIEC strains. The mean SBF index was higher for AIEC than for non-AIEC strains, as corroborated by one-way ANOVA $(P=0.012)$.

was calculated. Although the majority of AIEC strains were motile $(81.5 \%)$, no significant differences were observed in comparison to non-AIEC strains $(65.8 \%)$. Moreover, no interaction among these factors was detected by applying a factorial ANOVA. Therefore, motility and adherence/invasion capacity were independent factors associated with biofilm formation.

\section{Serogroups associated with higher biofilm producing abilities}

As shown in Figure 4, O83, followed by O22, showed the highest mean SBF indices. Regardless the AIEC phenotype and origin of the strains (intestinal or extraintestinal and non-IBD or CD associated), all the strains of O22 and O83 serogroup were found to be moderate-strong biofilm producers.

Other serogroups with mean SBF that fell into the 'moderate' category were: O2, O6, O14, O18, O25, O159, and O166. However, some strains that were unable to form biofilms were detected amongst these serogroups. For some serogroups such as $\mathrm{O} 2$ and $\mathrm{O} 14$ those strains classified as weak biofilm producers were particularly those nonmotile $\mathrm{O} 2 / \mathrm{O} 14$ strains. In turn, strains with weak to strong biofilm formation abilities amongst the $\mathrm{O} 6$ strains belonged to a certain serotype (O6:H31) and this serotype was not present amongst the categories 'moderate' or 'strong' biofilm producers. Nevertheless, very few strains have been analyzed for some of these serogroups (O2, O14, O18, O25, O159, and O166) due to the nature of the strains isolated from the intestinal mucosa, thus no robust conclusions can be extracted for them.

\section{Distribution of virulence-associated genes and phylogroups within biofilm producers}

Of the 65 E. coli strains used in this study, 45 (69.2\%) harboured more than two virulence-associated genes in addition to fimH; thus, these strains are considered an extraintestinal pathogenic E. coli according to the definition of Johnson et al [21]. Virulence-associated gene distribution was similar between biofilm producers (moderate-strong) and non-biofilm producers (weak), with the exception of adherence factor $s f a / f o c D E$ (S or F1C fimbriae) and the invasion-associated gene ibeA (Table 4), which were more prevalent in biofilm-forming strains $(\mathrm{P}$ $=0.003$ and $\mathrm{P}=0.017$, respectively).

Although the E. coli collection studied was mainly composed of B2 (52.3\%) and D (20\%) phylotypes, significant differences were observed between the two categories of biofilm producers. As shown in Table 4, the B2 phylogroup was more frequent in moderate-strong biofilm forming strains (80.8\% vs. 34.2\%; P < 0.001), whereas A and $\mathrm{D}$ phylogroups were more frequent within weak biofilm producers.

\section{Discussion}

In this work, we describe the biofilm formation capacity of a recently described pathovar, adherent-invasive E. coli (AIEC), which is associated with Crohn's disease. The main result was that AIEC strains have stronger biofilm formation abilities than other E. coli strains isolated from the intestinal mucosa (non-AIEC). The latter share genotypic and phenotypic traits with AIEC [15] but lack the properties described for the pathovar: (i) adhesion to and invasion of intestinal epithelial cells in vitro, (ii) survival and replication capacity within macrophages without causing host-cell death, and (iii) induction of TNF- $\alpha$ release [11]. We also analyzed the relationship between biofilm formation, AIEC phenotype, serotype, and phylogroup, and the presence of virulence-associated genes.

As observed by other authors [22,23], motility was a crucial factor for biofilm formation because none of the nonmotile strains were able to form biofilms (Table 3 ). This observation was further supported by the experiments performed with the isogenic mutant LF82- $\Delta$ fliC. Moreover, all 14 strains with $\mathrm{H} 1$ flagellar antigen were moderatestrong biofilm producers, in contrast to $46.2 \%$ of motile non-H1 types. Therefore, H1 flagellar antigen conferred, either directly or indirectly, an advantageous trait to form biofilms. Although motility was a necessary requirement for biofilm formation, it was not sufficient; 21 out of 47 

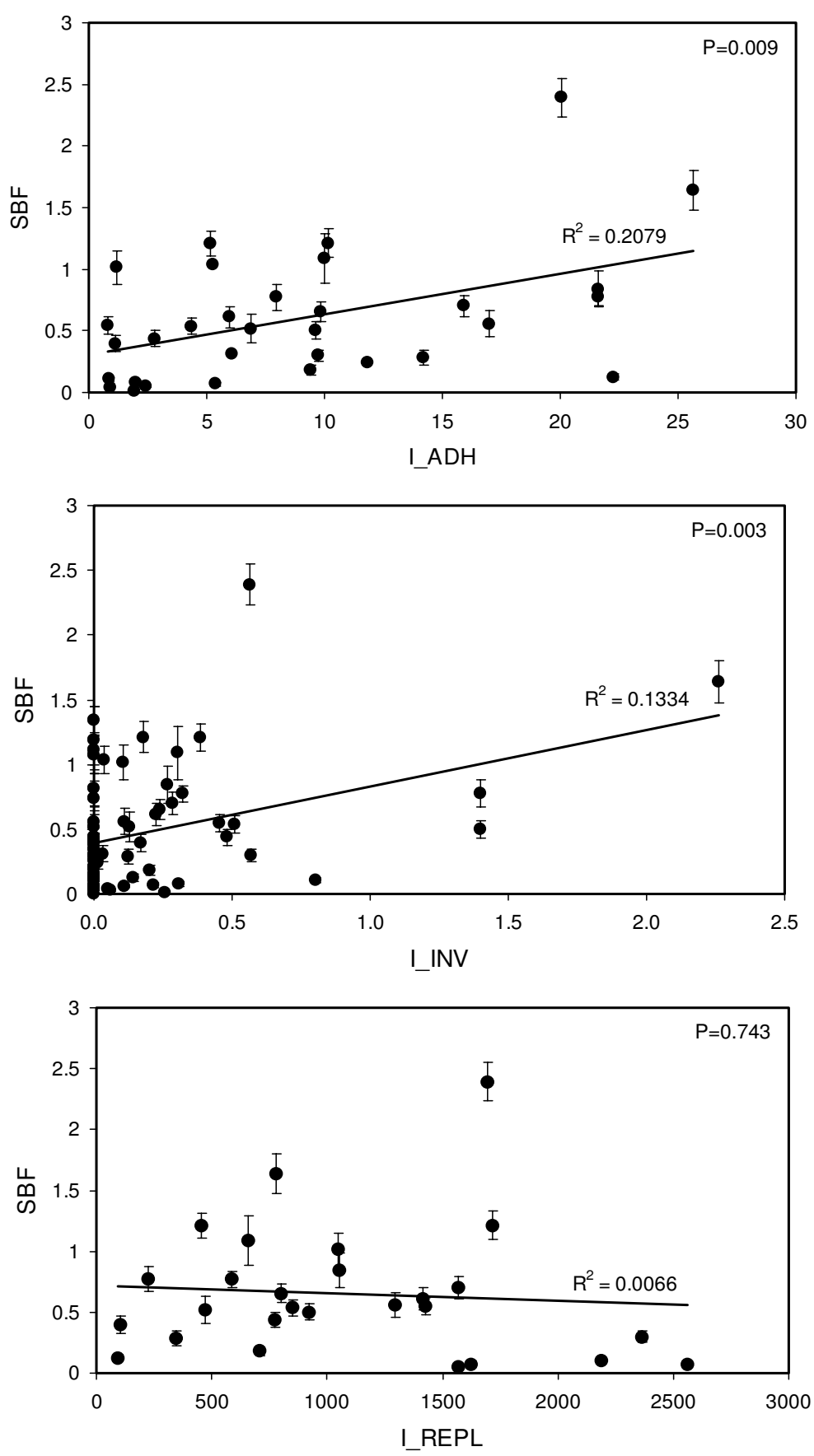

Figure 2

Correlations between biofilm formation and the adhesion, invasion, and intra-macrophage replication abilities of both AIEC and non-AIEC strains. Adhesion and invasion indices correlated positively with biofilm formation capacity, whereas intra-macrophage survival and replication did not. Adhesion index was calculated as: I_ADH = attached bacterial cells/ intestinal cell; invasion index as: $I \_I N V(\%)=\left(\right.$ intracellular bacteria $/ 4 \times 10^{6}$ bacteria inoculated $) \times 100$; and replication index as: I_REPL $=\left(\right.$ cfu ml-1 at $24 \mathrm{~h}_{\mathrm{cfu} \mathrm{ml}}{ }^{-1}$ at I h$) \times 100$. 
Table 3: Frequency of strains according to their motility capacity and flagellar antigen type within biofilm producers and nonproducers.

\begin{tabular}{|c|c|c|c|c|c|}
\hline \multicolumn{6}{|c|}{ Biofilm formation category } \\
\hline \multirow[b]{2}{*}{ Motility/H type } & \multicolumn{2}{|c|}{$\begin{array}{l}\text { Moderate-Strong } \\
(\mathbf{N}=\mathbf{2 6})\end{array}$} & \multicolumn{2}{|c|}{$\begin{array}{c}\text { Weak } \\
(N=39)\end{array}$} & \multirow[b]{2}{*}{$\mathbf{P}$} \\
\hline & $\mathbf{N}$ & (\%) & $\mathbf{N}$ & (\%) & \\
\hline $\mathrm{H}-(\mathrm{N}=18)$ & 0 & $(0)$ & 18 & $(46.2)$ & $<0.00 \mathrm{I}^{a}, 0.003^{b}$ \\
\hline $\mathrm{HI}(\mathrm{N}=14)$ & 14 & $(53.8)$ & 0 & $(0)$ & $<0.001{ }^{a},<\left.0.00\right|^{c}$ \\
\hline $\mathrm{Hx}(\mathrm{N}=33)$ & 12 & $(46.2)$ & 21 & $(53.8)$ & $<0.001^{c}, 0.003^{b}$ \\
\hline
\end{tabular}

Abbreviators: $\mathrm{H}$-: nonmotile strains; $\mathrm{HI}$ : motile and $\mathrm{HI}$ flagellar type; $\mathrm{Hx}$ : motile and any flagellar type except $\mathrm{HI}$. ${ }^{a}$ significance between $\mathrm{H}$ - and $\mathrm{HI}$;

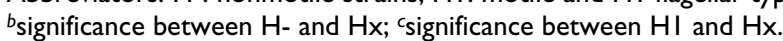

motile strains were weak biofilm producers, indicating that additional factors are needed. In addition, strains with $\mathrm{O} 2, \mathrm{O} 6, \mathrm{O} 14, \mathrm{O} 18, \mathrm{O} 22, \mathrm{O} 25, \mathrm{O} 83, \mathrm{O} 159$ and $\mathrm{O} 166$ serogroups were found amongst the biofilm producers, in accordance with previous studies [24,25]. Interestingly, the highest mean SBFs index was achieved by four strains that belonged to the 083 serogroup, in particular the O83:H1 serotype, being all the strains classified as strong biofilm producers. This group included two AIEC strains (AIEC reference strain LF82 [11], and the sepsis-associated

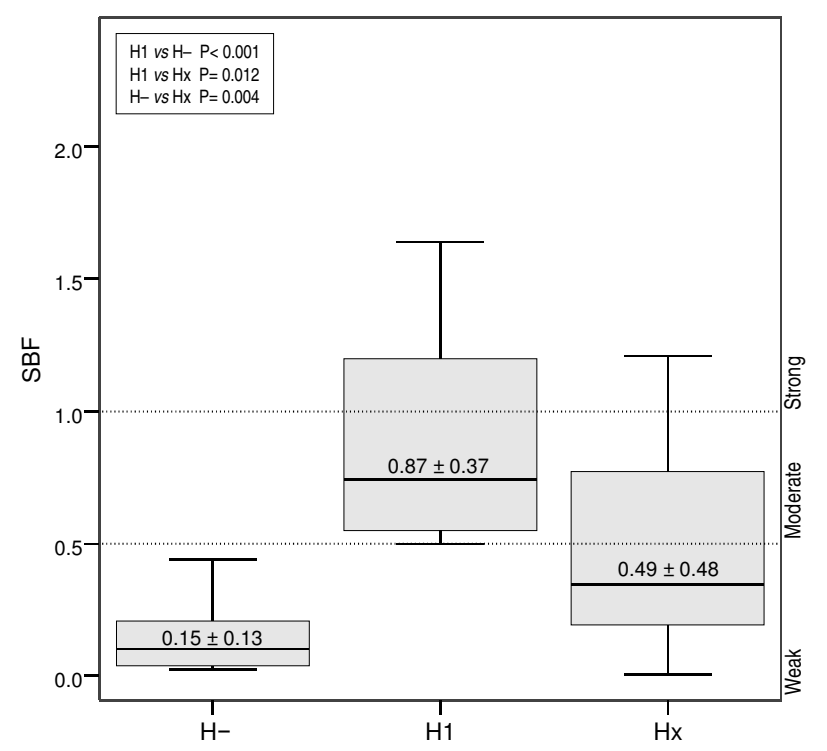

Figure 3

Mean SBF index of motile and nonmotile strains irrespectively of their AIEC phenotype. SBF indices were higher in motile strains, especially $\mathrm{HI}$ serotypes, than nonmotile strains. $\mathrm{H}$-: nonmotile strains; $\mathrm{HI}$ : motile and $\mathrm{HI}$ flagellar type; $\mathrm{Hx}$ : motile and any flagellar type except for $\mathrm{HI}$. strain PP16) and two non-AIEC strains (ECG-009 (isolated from two different CD patients) and ECG-043 (isolated from one non-IBD control) [15].

Some associations between biofilm-formation potential and some virulence-associated genes have been already described [24,26-32]. In agreement with previous studies [25], the adhesin-coding gene $s f a / f o c \mathrm{DE}$ was more frequently detected amongst biofilm producers. In addition, the gene ibeA, required for invasion in meningitis/sepsisassociated E. coli (MNEC) [33,34], was more prevalent amongst strong biofilm producers. Interestingly, ibeA, in conjunction with fimH and fimA $v_{M T 78}$, are virulence factors present in AIEC strain LF82 $[16,35]$.

Phylogenetic analyses have shown that $E$. coli strains fall into four main phylogenetic groups (A, B1, B2, and D) and that virulent ExPEC strains mainly belong to group $\mathrm{B} 2$ and, to a lesser extent, group $\mathrm{D}$, whereas most commensal strains belong to group A $[33,36]$. Although B2 was the most abundant phylotype within the E. coli collection, B2 phylotypes were significantly more prevalent amongst moderate-strong biofilm producers than weak biofilm producers $(\mathrm{P}<0.001)$, which were enriched in $\mathrm{A}$ and $\mathrm{D}$ phylotypes $(\mathrm{P}=0.052$ and $\mathrm{P}=0.006$ respectively). Of note, $\mathrm{B} 2+\mathrm{D}$ phylotypes are also more prevalent amongst E. coli strains from patients with CD or ulcerative colitis than in non-IBD controls [37].

The positive correlation between the levels of adhesion and invasion and the higher SBF indices lead to postulate that the machinery implicated to achieve the "AIEC phenotype" could share some factors necessary for biofilm formation, such as type 1 pili and flagella. Another possibility is that both processes could be related to a coordinated expression, for instance, by the EnvZ/OmpR regulatory system. Rohlion et al [38] recently proposed a model in which OmpC, a porin regulated by EnvZ/ 


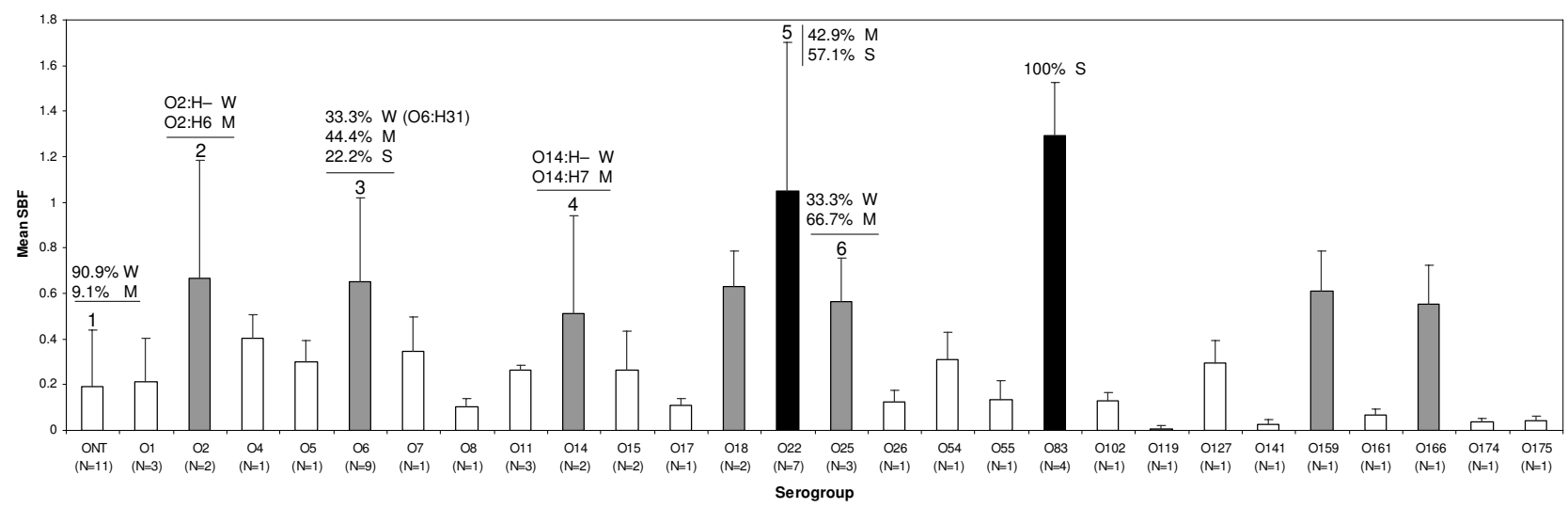

\begin{abstract}
Figure 4
Mean SBF index of the strains classified by their serogroup. White bars: Serogroups with mean SBF that falls into 'weak' biofilm formation category. Grey bars: Serogroups with mean SBF that falls into 'moderate' biofilm formation category. Black bars: Serogroups with mean SBF that falls into 'strong' biofilm formation category. The serotype of those $E$. coli strains that showed different biofilm formation category than the mean SBF for the serogroup is specified: I: Only AIECI7 (ONT:HNT) strain was classified as 'moderate' biofilm producer (M). 2: Nonmotile ECG-04I (O2:H-) strain was classified as 'weak' biofilm producer (W). 3: Three strains with $06: \mathrm{H} 3 \mathrm{I}$ serotype were classified as 'weak' biofilm producers, whereas strains with $\mathrm{O6}: \mathrm{HI}, \mathrm{O} 6: \mathrm{H} 5$ and O6:HNT serotypes were 'moderate' or 'strong' biofilm producers. 4: Nonmotile ECG-054 $(\mathrm{Ol} 4: \mathrm{H}-)$ was 'weak' biofilm producer (W). 5: Three strains were 'moderate' (O22:HI) and 4 strains 'strong' (O22:HI, O22:H7, and O22:HI8) biofilm producers. 6: AIEC08 $(\mathrm{O} 25: \mathrm{H} 4)$ was classified as 'weak' biofilm producer.
\end{abstract}

OmpR, has been implicated in the adherence-invasiveness of AIEC, and this system is also known to play an important role in biofilm formation [39]. The biofilm formation could also be dependent on the cyclic di-GMP concentration which was recently reported to regulate the expression of type 1 pili and flagella in AIEC reference strain LF82 [40].

Biofilms in the human gut are thought to play an agonistic role with the host [18], being necessary to achieve an homeostatic situation and appropriate gut physiology. Nevertheless, previous studies have highlighted the increased biofilm formation in patients with CD with respect to control subjects [41]. Moreover, the composition of the mucosa-associated microbiota is altered with respect to that of non-IBD controls [42]. It is widely accepted that the intestinal microbiota is essential to elicit the inflammation; however, the specific role of intestinal biofilms in CD is still uncertain. Changes in the composition and abundance of mucosa-associated biofilms have been proposed either to play a role in the onset or perpetuation of CD [41,43-45] or to be a consequence of the defective immune regulation in CD patients $[18,46,47]$. Because we have analyzed the biofilm formation capacity of a collection of AIEC and non-AIEC strains using an in vitro method we can deduce that the ability of AIEC to form biofilms is irrespective of host factors. However, in vivo experiments would give interesting insights into the pathogenesis of AIEC in CD. Biofilm formation of AIEC in human gut, if confirmed, would confer to the pathovar an advantage for colonization of the intestine. Consequently, given the pathogenic behavior of AIEC, a more stable colonization would increase their probability of invading the intestinal epithelium and further trigger mucosal inflammation and, possibly, granuloma formation. In this sense, and speculatively, biofilm formation could contribute to AIEC pathogenesis.

\section{Conclusion}

A novel phenotypic trait of AIEC pathovar was described in this work. Biofilm production ability of AIEC strains could be an additional trait involved in their pathogenesis. Further investigations to detect AIEC specific genetic determinants involved in biofilm formation and to analyze the genetic regulatory processes are essential to fully understand AIEC pathogenesis and elucidate a possible role of AIEC in CD.

\section{Methods}

\section{Bacterial strains}

Amongst the collection of $65 \mathrm{E}$. coli strains, sixty-one (93.8\%) were isolated from human intestinal mucosa in previous studies $[15,48]$. In particular, 35 strains (16 of them were AIEC) came from CD patients, one (which belonged to AIEC pathovar) came from a patient suffering from ulcerative colitis, and 25 (of which 6 were AIEC) came from non-IBD controls. Also included were four additional AIEC strains that came from patients with 
Table 4: Comparison of virulence gene prevalence and phylogroup between weak and moderate-strong biofilm producers.

\begin{tabular}{|c|c|c|c|c|c|c|c|}
\hline \multirow[b]{3}{*}{ Virulence gene } & \multicolumn{7}{|c|}{ Biofilm formation category } \\
\hline & \multicolumn{2}{|c|}{$\begin{array}{c}\text { Total } \\
(\mathbf{N}=65)\end{array}$} & \multicolumn{2}{|c|}{$\begin{array}{l}\text { Moderate-Strong } \\
\quad(\mathbf{N}=\mathbf{2 6})\end{array}$} & \multicolumn{2}{|c|}{$\begin{array}{c}\text { Weak } \\
(N=39)\end{array}$} & \multirow[t]{2}{*}{$\mathbf{P}$} \\
\hline & $\mathbf{N}$ & (\%) & $\mathbf{N}$ & (\%) & $\mathbf{N}$ & (\%) & \\
\hline \multicolumn{8}{|c|}{ Adhesin-encoding genes } \\
\hline papC & 32 & $(49.2)$ & 11 & $(42.3)$ & 21 & $(53.8)$ & 0.255 \\
\hline sfalfocDE & 13 & $(20.0)$ & 10 & $(38.5)$ & 3 & (7.7) & 0.003 \\
\hline$a f a / d r a B C$ & 8 & $(12.3)$ & 2 & (7.7) & 6 & $(15.4)$ & 0.301 \\
\hline $\mathrm{fimH}$ & 62 & $(95.4)$ & 26 & $(100)$ & 36 & $(92.3)$ & 0.209 \\
\hline $\mathrm{fimAv}_{M T 78}$ & 14 & $(21.5)$ & 6 & $(23.1)$ & 8 & $(20.5)$ & 0.520 \\
\hline \multicolumn{8}{|c|}{ Protectin/invasion-encoding genes } \\
\hline ibeA & 9 & $(13.8)$ & 7 & $(26.9)$ & 2 & $(5.1)$ & 0.017 \\
\hline KI neuC & 9 & $(13.8)$ & 3 & $(11.5)$ & 6 & $(15.4)$ & 0.478 \\
\hline \multicolumn{8}{|c|}{ Siderophore-related genes } \\
\hline$i u c D$ & 37 & $(56.9)$ & 13 & $(50.0)$ & 24 & $(61.5)$ & 0.253 \\
\hline \multicolumn{8}{|c|}{ Toxin-encoding genes } \\
\hline hlyA & 15 & $(23.1)$ & 9 & $(34.6)$ & 6 & $(15.4)$ & 0.067 \\
\hline cnfl & 15 & $(23.1)$ & 9 & $(34.6)$ & 6 & $(15.4)$ & 0.067 \\
\hline$c d t B$ & 5 & (7.7) & 3 & $(11.5)$ & 2 & $(5.1)$ & 0.312 \\
\hline \multicolumn{8}{|l|}{ Phylogroup } \\
\hline A & 9 & $(13.8)$ & 1 & $(3.8)$ & 8 & $(2 I . I)$ & 0.052 \\
\hline BI & 8 & $(12.3)$ & 3 & $(11.5)$ & 5 & $(13.2)$ & 0.583 \\
\hline B2 & 34 & $(52.3)$ & 21 & $(80.8)$ & 13 & $(34.2)$ & $<0.001$ \\
\hline$D$ & 13 & $(20.0)$ & 1 & $(3.8)$ & 12 & $(31.6)$ & 0.006 \\
\hline
\end{tabular}

extraintestinal infection (two with sepsis and two with urinary tract infection $[49,50])$. AIEC reference strain LF82 and the isogenic mutant LF82- $\Delta$ fliC were used as controls. Relevant characteristics of the strains that were known prior to this study are compiled in Table 1.

All procedures were approved by the ethics committee of clinical investigation of the Hospital Josep Trueta of Girona in compliance with the Helsinki declaration.

\section{Biofilm formation assay}

Biofilm formation assays were performed using a previously described method [26] with some modifications [25]. Strains were grown overnight in Luria-Bertani broth with $5 \mathrm{~g} \mathrm{l}^{-1}$ of glucose (Sigma-Aldrich, St. Louis, USA) at $35.5^{\circ} \mathrm{C}$, then $1 / 100$ dilutions were made in M63 minimal medium (US Biological, Swampscott, USA) supplemented with $8 \mathrm{~g} \mathrm{l}^{-1}(0.8 \%)$ glucose. Then, $130-\mu \mathrm{l}$ aliquots were placed in wells of non-cell-treated polystyrene 
microtiter plates (Greiner Bio-one, Stuttgart, Germany) and incubated overnight at $30^{\circ} \mathrm{C}$ without shaking. Afterwards, growth optical densities (OD) were read at 630 $\mathrm{nm}$; then the wells were washed once, adhered bacteria were stained with $1 \%$ crystal violet solubilised in ethanol, and ODs read at $570 \mathrm{~nm}$. Biofilm measurements were calculated using the formula $S B F=(A B-C W) / G$, in which $S B F$ is the specific biofilm formation, $A B$ is the $\mathrm{OD}_{570 \mathrm{~nm}}$ of the attached and stained bacteria, $C W$ is the $\mathrm{OD}_{570 \mathrm{~nm}}$ of the stained control wells containing only bacteria-free medium (to eliminate unspecific or abiotic OD values), and $G$ is the $O_{630 \mathrm{~nm}}$ of cell growth in broth $[51,52]$. For each assay, 16 wells per strain were analyzed, and the assays were performed in triplicate, which resulted in a total of 48 wells per each tested strain and control. The degree of biofilm production was classified in three categories: weak $(\mathrm{SBF} \leq 0.5)$, moderate $(0.5>\mathrm{SBF} \leq 1)$, and strong (SBF > 1).

\section{Adhesion and invasion assays in epithelial cells Intestine- 407}

The epithelial cell line Intestine-407 was used for adhesion and invasion assays (ATCC accession number CCL$\left.6^{\mathrm{TM}}\right)$. Cell culture was performed as described previously [48]. To quantify adhesion and invasion properties, a gentamicin protection assay were performed as previously described [48]. Briefly, 24-well plates containing $4 \times 10^{5}$ cells/well incubated for 20 hours were infected at a multiplicity of infection of 10. Duplicated plates, for adhesion and invasion assays were incubated for 3 hours at $37^{\circ} \mathrm{C}$. For bacterial adhesion assays, cell monolayers were washed 5 times with PBS and lysed with $1 \%$ Triton X-100. Adhered bacteria were quantified by plating them in nutrient agar. Plating was performed in a maximum period of 30 minutes to avoid bacterial lysis by Triton X100. Adherence ability (I_ADH) was determined as the mean number of bacteria per cell. For bacterial invasion assays, monolayers were washed twice with PBS after 3 hours of infection, and fresh cell culture medium containing $100 \mu \mathrm{g} \mathrm{ml}^{-1}$ of gentamicin was added for 1 hour to kill extracellular bacteria. After cell lysis with $1 \%$ Triton X100 , the number of intracellular bacteria was also determined by plating. All assays were performed in triplicate. The invasive ability was expressed as the percentage of intracellular E. coli compared with the initial inoculum, taken as $100 \%$ : I_INV $(\%)=\left(\right.$ intracellular bacteria $/ 4 \times 10^{6}$ bacteria inoculated) $\times 100$.

\section{Survival and replication in macrophages $\mathbf{} 774$}

The macrophage-like J774A.1 cell line (ATCC accession number TIB-67 ${ }^{\mathrm{TM}}$ ) was used as a model for E. coli survival and replication assays. Cell culture was performed as described previously [53]. E. coli isolates with known adherence and invasion properties were then checked for their capability to survive and replicate inside macro- phages as previously described [11]. Macrophages were seeded at $2 \times 10^{5}$ cells per well in two 24 -well plates and incubated for 20 hours. Once overnight medium was removed and fresh medium was added, bacteria were seeded at a multiplicity of infection of 10 . Centrifugation at $900 \mathrm{rpm}$ for 10 minutes, plus an additional incubation at $37^{\circ} \mathrm{C}$ for 10 minutes, was performed to assist the internalization of bacteria within macrophages. Non-phagocytosed bacteria were killed with gentamicin $\left(20 \mu \mathrm{g} \mathrm{ml}^{-1}\right)$, and intracellular bacteria were quantified as for invasion assays after 1 and 24 hours of infection. All assays were performed in triplicate. Results were expressed as the mean percentage of the number of bacteria recovered after 1 and $24 \mathrm{~h}$ post-infection compared with the initial inoculum, taken as 100\%: I_REPL (\%) $=\left(\mathrm{cfu} \mathrm{ml}^{-1}\right.$ at $24 \mathrm{~h} / \mathrm{cfu}$ $\mathrm{ml}^{-1}$ at $\left.1 \mathrm{~h}\right) \times 100$. Those strains with I_INV $>0.1$ and I_REPL $>100 \%$ were classified as AIEC in this study.

\section{Serotyping}

Determination of $\mathrm{O}$ and $\mathrm{H}$ antigens was carried out using the method previously described by Guinée et al. [54]. Strains which failed to achieve motility on semisolid medium were considered nonmotile and designated $\mathrm{H}$-.

\section{Phylotyping and virulence genotyping by $P C R$}

Determination of the major E. coli phylogenetic group (A, B1, B2, and D) was performed as previously described by Clermont et al [36].

Virulence gene carriage was analyzed as described elsewhere $[25,55]$ using primers specific for 11 genes that encode extraintestinal virulence factors characteristic of ExPEC. These included six adhesins (pyelonephritis-associated pili ( $p a p C), \mathrm{S}$ and F1C fimbriae ( $s f a / f o c D E)$, afimbrial Dr-binding adhesins (afa/draBC), type 1 fimbriae (fim $H$ ), and type 1 variant of avian pathogenic E. coli strain MT78 ( $f$ imA $\left.v_{\mathrm{MT78}}\right)$ ); three toxins (hlyA, cnf1, and $c d t B)$; and one aerobactin gene (iucD). They also included two protectin/invasion-encoding genes that corresponded to K1 kps variant (neuC) and brain microvascular endothelial cell invasion gene (ibeA). Specific genes for diarrhoeagenic $E$. coli pathovars were also screened (stx1, stx2, eae, bfpA, ipaH, pCDV432, eltA, and est).

\section{Statistical analyses}

Quantitative parameters, such as SBF, adhesion, and invasion indices were compared by one-way ANOVA. In cases for which the interaction between several factors was of interest, a factorial ANOVA was applied. Correlation between quantitative variables was assessed by Pearson correlation coefficient. Fisher's exact test (small contingency tables) or Pearson's $\mathrm{X}^{2}$ tests (frequencies higher than five within cells) were used to measure the significance of frequency values. 


\section{Authors' contributions}

MMM performed the adhesion and invasion assays, intramacrophage survival and replication assays, statistical analyses, and drafted the manuscript. PN and CP performed the biofilm formation assays. PN also participated in drafting the manuscript. JB, JEB and MB carried out the serotyping and virulence genotyping. XA contributed by giving a medical point of view to the discussion of results. JB, FS, ADM, and JGG were involved in the design and coordination of the study, participated in the revision of the manuscript, and gave final approval of the version to be published. All authors read and approved the final version.

\section{Acknowledgements}

This work was partially supported by the Spanish Ministry of Education and Science (SAF2006-004 I4), the Spanish Ministry of Health and Consumer Affairs (REIPI RD06/0008-1018 and FIS PI060059), the Autonomous Government of Galicia (Xunta de Galicia, 2007/000044-0, PGIDIT065TAL26I0IPR, 07MRU03626IPR), and the European Union (Program Alban, E05D055472BR). We gratefully thank Dr. Miguel Clavero (University of Girona) for statistical advice.

\section{References}

I. Economou M, Pappas G: New Global Map of Crohn's Disease: Genetic, Environmental, and Socioeconomic Correlations. Inflamm Bowel Dis 2008, I4(5):709-720.

2. Baumgart DC, Carding SR: Inflammatory bowel disease: cause and immunobiology. Lancet 2007, 369(9573): 1627-1640.

3. Xavier RJ, Podolsky DK: Unravelling the pathogenesis of inflammatory bowel disease. Nature 2007, 448(7 I 52):427-434.

4. Halfvarson J, Bodin L, Tysk C, Lindberg E, Järnerot G: Inflammatory bowel disease in a Swedish twin cohort: a long-term followup of concordance and clinical characteristics. Gastroenterology 2003, I 24(7): I 767-I773.

5. De Hertogh G, Aerssens J, Geboes K, Geboes K: Evidence for the involvement of infectious agents in the pathogenesis of Crohn's disease. World J Gastroenterol 2008, 14(6):845-852.

6. Hanauer S: Inflammatory Bowel Disease: Epidemiology, Pathogenesis, and Therapeutic Opportunities. Inflamm Bowel Dis 2006, 12:S3-S9.

7. Rutgeerts P, Goboes K, Peeters M, Hiele M, Penninckx F, Aerts R, Kerremans R, Vantrappen G: Effect of faecal stream diversion on recurrence of Crohn's disease in the neoterminal ileum. Lancet |99|, 338(8770):77|-774.

8. Rutgeerts P, Hiele M, Geboes K, Peeters M, Penninckx F, Aerts R, Kerremans R: Controlled trial of metronidazole treatment for prevention of crohn's recurrence after ileal resection. Gastroenterology 1995, 108(6): 1617-1621.

9. Sartor RB: Microbial Influences in Inflammatory Bowel Diseases. Gastroenterology 2008, 134(2):577-594.

10. Sellon RK, Tonkonogy S, Schultz M, Dieleman LA, Grenther W, Balish E, Rennick DM, Sartor RB: Resident Enteric Bacteria Are Necessary for Development of Spontaneous Colitis and Immune System Activation in Interleukin-10-Deficient Mice. Infect Immun 1998, 66(I I):5224-523I.

II. Darfeuille-Michaud A, Boudeau J, Bulois P, Neut C, Glasser A-L, Barnich N, Bringer M-A, Swidsinski A, Beaugerie L, Colombel J-F: High prevalence of Adherent-Invasive Escherichia coli Associated With Ileal Mucosa in Crohn's Disease. Gastroenterology 2004, 127(2):4|2-42|.

12. Martin HM, Campbell B], Hart CA, Mpofu C, Nayar M, Singh R, Englyst $\mathrm{H}$, Williams HF, Rhodes JM: Enhanced Escherichia coli adherence and invasion in Crohn's disease and colon cancer. Gastroenterology 2004, I 27(I):80-93.

13. Baumgart M, Dogan B, Rishniw M, Weitzman G, Bosworth B, Yantiss R, Orsi RH, Wiedmann M, McDonough P, Kim SG, Berg D, Schukken Y, Scherl E, Simpson KW: Culture independent analysis of ileal mucosa reveals a selective increase in invasive Escherichia coli of novel phylogeny relative to depletion of Clostridiales in Crohn's disease involving the ileum. ISME J 2007, I(5):403-4I8.

14. Sasaki M, Sitaraman SV, Babbin BA, Gerner-Smidt P, Ribot EM, Garrett N, Alpern JA, Akyildiz A, Theiss AL, Nusrat A, Klapproth J-MA: Invasive Escherichia coli are a feature of Crohn's disease. Lab Invest 2007, 87(10): 1042-1054.

15. Martinez-Medina M, Aldeguer X, Lopez-Siles M, González-Huix F, López-Oliu C, Dahbi G, Blanco JE, Blanco J, Garcia-Gil LJ, DarfeuilleMichaud A: Molecular diversity of Escherichia coli in the human gut: new ecological evidence supporting the role of adherent-invasive $E$. coli (AIEC) in Crohn's disease. Inflamm Bowel Dis 2009, I 5(6):872-882.

16. Simpson KW, Dogan B, Rishniw M, Goldstein RE, Klaessig S, McDonough PL, German AJ, Yates RM, Russell DG, Johnson SE, Berg DE, Harel J, Bruant G, McDonough SP, Schukken YH: Adherent and Invasive Escherichia coli Is Associated with Granulomatous Colitis in Boxer Dogs. Infect Immun 2006, 74(8):4778-4792.

17. Hall-Stoodley L, Stoodley P: Biofilm formation and dispersal and the transmission of human pathogens. Trends Microbiol 2005, 13(1):7-10.

18. Everett ML, Palestrant D, Miller SE, Bollinger RR, Parker W: Immune exclusion and immune inclusion: a new model of host-bacterial interactions in the gut. Clinical Applied Imm Rev 2004, 4(5):32I-332.

19. Anderson GG, Palermo JJ, Schilling JD, Roth R, Heuser J, Hultgren SJ: Intracellular bacterial biofilm-like pods in urinary tract infections. Science 2003, 30 I(5629): 105-107.

20. Kaper JB, Nataro JP, Mobley HLT: Pathogenic Escherichia coli. Nat Rev Microbiol 2004, 2(2): I23-I 40.

21. Johnson JR, Murray AC, Gajewski A, Sullivan M, Snippes P, Kuskowski MA, Smith KE: Isolation and Molecular Characterization of Nalidixic Acid-Resistant Extraintestinal Pathogenic Escherichia coli from Retail Chicken Products. Antimicrob Agents Chemother 2003, 47(7):2161-2168.

22. Pratt LA, Kolter R: Genetic analysis of Escherichia coli biofilm formation: roles of flagella, motility, chemotaxis and type $I$ pili. Mol Microbiol 1998, 30(2):285-293.

23. Van Houdt R, Michiels CW: Role of bacterial cell surface structures in Escherichia coli biofilm formation. Res Microbiol 2005, 156(5-6):626-633.

24. Kanamaru S, Kurazono H, Terai A, Monden K, Kumon H, Mizunoe Y, Ogawa O, Yamamoto S: Increased biofilm formation in Escherichia coli isolated from acute prostatitis. Int J Antimicrob Agents 2006, 28(Supplement I):2I-25.

25. Naves P, del Prado G, Huelves L, Gracia M, Ruiz V, Blanco J, Dahbi G, Blanco M, del Carmen Ponte M, Soriano F: Correlation between virulence factors and in vitro biofilm formation by Escherichia coli strains. Microb Pathog 2008, 45(2):86-91.

26. Danese $P$, Pratt $L$, Dove $S$, Kolter R: The outer membrane protein, Antigen 43, mediates cell-to-cell interactions within Escherichia coli biofilms. Mol Microbiol 2000, 37(2):424-432.

27. Ong C-LY, Ulett GC, Mabbett AN, Beatson SA, Webb RI, Monaghan W, Nimmo GR, Looke DF, McEwan AG, Schembri MA: Identification of Type 3 Fimbriae in Uropathogenic Escherichia coli Reveals a Role in Biofilm Formation. J Bacteriol 2008, 190(3): 1054-1063.

28. Schembri MA, Dalsgaard D, Klemm P: Capsule Shields the Function of Short Bacterial Adhesins. J Bacteriol 2004, | 86(5): $1249-1257$

29. Soto SM, Smithson A, Martinez JA, Horcajada JP, Mensa J, Vila J: Biofilm Formation in Uropathogenic Escherichia coli Strains: Relationship With Prostatitis, Urovirulence Factors and Antimicrobial Resistance. J Urol 2007, I77(1):365-368.

30. Ulett GC, Mabbett AN, Fung KC, Webb RI, Schembri MA: The role of F9 fimbriae of uropathogenic Escherichia coli in biofilm formation. Microbiology 2007, I53(7):232I-233I.

31. Ulett GC, Valle J, Beloin C, Sherlock O, Ghigo J-M, Schembri MA: Functional Analysis of Antigen 43 in Uropathogenic Escherichia coli Reveals a Role in Long-Term Persistence in the Urinary Tract. Infect Immun 2007, 75(7):3233-3244.

32. Vianney A, Jubelin G, Renault S, Dorel C, Lejeune P, Lazzaroni JC: Escherichia coli tol and rcs genes participate in the complex network affecting curli synthesis. Microbiology 2005, I 5 I (7):2487-2497. 
33. Bidet P, Mahjoub-Messai F, Blanco J, Blanco J, Dehem M, Aujard Y, Bingen $E$, Bonacorsi $S$ : Combined multilocus sequence typing and $O$ serogrouping distinguishes Escherichia coli subtypes associated with infant urosepsis and/or meningitis. J Infect Dis 2007, I 96(2):297-303.

34. Xie Y, Kim KJ, Kim KS: Current concepts on Escherichia coli KI translocation of the blood-brain barrier. FEMS Immunol Med Microbiol 2004, 42(3):27I-279.

35. Boudeau J, Barnich N, Darfeuille-Michaud A: Type I pili-mediated adherence of Escherichia coli strain LF82 isolated from Crohn's disease is involved in bacterial invasion of intestinal epithelial cells. Mol Microbiol 200I, 39(5): I272-I 284.

36. Clermont O, Bonacorsi S, Bingen E: Rapid and Simple Determination of the Escherichia coli Phylogenetic Group. Appl Environ Microbiol 2000, 66( I 0):4555-4558.

37. Kotlowski R, Bernstein CN, Sepehri S, Krause DO: High prevalence of Escherichia coli belonging to the B2+D phylogenetic group in inflammatory bowel disease. Gut 2007, 56(5):669-675.

38. Rolhion N, Carvalho FA, Darfeuille-Michaud A: OmpC and the sigma(E) regulatory pathway are involved in adhesion and invasion of the Crohn's disease-associated Escherichia colt strain LF82. Mol Microbiol 2007, 63(6): 1684-1700.

39. Pruss BM, Besemann C, Denton A, Wolfe Al: A Complex Transcription Network Controls the Early Stages of Biofilm Development by Escherichia coli. J Bacteriol 2006 , I 88(I I):373 I-3739.

40. Claret L, Miquel S, Vieille N, Ryjenkov DA, Gomelsky M, DarfeuilleMichaud A: The flagellar sigma factor FliA regulates adhesion and invasion of Crohn disease-associated Escherichia coli via a cyclic dimeric GMP-dependent pathway. J Biol Chem 2007, 282(46):33275-33283.

41. Swidsinski A, Ladhoff A, Pernthaler A, Swidsinski S, Loening-Baucke V, Ortner M, Weber J, Hoffmann U, Schreiber S, Dietel M, Lochs H Mucosal flora in inflammatory bowel disease. Gastroenterology 2002, I 22(I):44-54.

42. Martinez-Medina M, Aldeguer X, Gonzalez-Huix F, Acero D, GarciaGil LJ: Abnormal microbiota composition in the ileocolonic mucosa of Crohn's disease patients as revealed by polymerase chain reaction-denaturing gradient gel electrophoresis. Inflamm Bowel Dis 2006, I 2( I 2): I | 36- I | 45.

43. Dicksved J, Halfvarson J, Rosenquist M, Jarnerot G, Tysk C, Apajalahti $J$, Engstrand L, Jansson JK: Molecular analysis of the gut microbiota of identical twins with Crohn's disease. ISME J 2008, 2(7):716-727.

44. Kleessen B, Kroesen A, Buhr $H$, Blaut M: Mucosal and invading bacteria in patients with inflammatory bowel disease compared with controls. Scand J Gastroenterol 2002, 37(9): |034-|04|.

45. Schultsz C, Berg FM van den, ten Kate FW, Tytgat GNJ, Dankert J: The intestinal mucus layer from patients with inflammatory bowel disease harbors high numbers of bacteria compared with controls. Gastroenterology 1999, II 7(5):1089-1097.

46. Lupp C, Robertson ML, Wickham ME, Sekirov I, Champion OL, Gaynor EC, Finlay BB: Host-mediated inflammation disrupts the intestinal microbiota and promotes the overgrowth of Enterobacteriaceae. Cell Host Microbe 2007, 2(2): I 19-129.

47. Wehkamp J, Stange EF: Is there a role for defensins in IBD? Inflamm Bow Dis 2008, I4(S2):S85-S87.

48. Boudeau J, Glasser A-L, Masseret E, joly B, Darfeuille-Michaud A: Invasive ability of an Escherichia coli strain isolated from the ileal mucosa of a patient with Crohn's disease. Infect Immun 1999, 67(9):4499-4509.

49. Blanco M, Blanco JE, Alonso MP, Mora A, Balsalobre C, Munoa F, Juárez $A$, Blanco J: Detection of pap, sfa and afa adhesin-encoding operons in uropathogenic Escherichia coli strains: Relationship with expression of adhesins and production of toxins. Res Microbiol I 997, I 48(9):745-755.

50. Nicolas-Chanoine $M-H$, Blanco J, Leflon-Guibout $V$, Demarty $R$, Alonso MP, Canica MM, Park Y-j, Lavigne J-P, Pitout J, Johnson JR: Intercontinental emergence of Escherichia coli clone O25:H4-STI3I producing CTX-M-I5. I Antimicrob Chemother 2008, 6 I(2):273-28I.

5I. Naves P, Prado Gd, Huelves L, Gracia M, Ruiz V, Blanco J, RodríguezCerrato V, Ponte MC, Soriano F: Measurement of biofilm formation by clinical isolates of Escherichia coli is method-dependent. J Appl Microbiol 2008, I05(2):585-590.
52. Niu C, Gilbert ES: Colorimetric Method for Identifying Plant Essential Oil Components That Affect Biofilm Formation and Structure. Appl Environ Microbiol 2004, 70( I 2):695I-6956.

53. Glasser A-L, Boudeau J, Barnich N, Perruchot M-H, Colombel J-F, Darfeuille-Michaud A: Adherent Invasive Escherichia coli Strains from Patients with Crohn's Disease Survive and Replicate within Macrophages without Inducing Host Cell Death. Infect Immun 200I, 69(9):5529-5537.

54. Guinée PA, Agterberg CM, Jansen WH: Escherichia coli $\mathbf{O}$ antigen typing by means of a mechanized microtechnique. Appl Microbiol 1972, 24(I): I27-I3|.

55. Blanco M, Blanco J, Dahbi G, Alonso M, Mora A, Coira M, Madrid C, Juárez $A$, Bernárdez M, González E, Blanco J: Identification of two new intimin types in atypical enteropathogenic Escherichia coli. Int Microbiol 2006, 9(2): 103-II0.
Publish with Biomed Central and every scientist can read your work free of charge

"BioMed Central will be the most significant development for disseminating the results of biomedical research in our lifetime. "

Sir Paul Nurse, Cancer Research UK

Your research papers will be:

- available free of charge to the entire biomedical community

- peer reviewed and published immediately upon acceptance

- cited in PubMed and archived on PubMed Central

- yours - you keep the copyright
BioMedcentral 